valescent home by all means do so: now, perhaps, your drugs may have a chance. One more quotation, though in a very different sphere of life, may help to illustrate our point. A young lady aged nineteen, wealthy and of high social position, came in January under the caro of an eminent physician skilled in chest complaints. She complained of prostration, palpitation, and other phenomena, and on examination was found to have slight irregularity of the cardiac action, with a soft bruit at the apex. After three months of treatment the condition of affairs was but little changed. One morning in April the housekeeper had occasion to call and see me, and she made this interesting statement: "The doctor says her ladyship has got a slight form of heart disease, but I know a young gentleman who, if he would only come forward, could do more for her heart than all the doctor's medicines." Curiously enough, on the following week the young gentleman did come forward, and the eminent physician lost his patient. I might multiply these instances, I might refer to the idiosyncrasies of various patients, but I have said enough to show the impracticability of following routine practice, and the absolute necessity of estimating both the disease and the patient. Throughout this address my aim has been rather to indicate lines of thought than to enter upon any comprehensive exposition of the many points we have touched upon.

And now my task is ended. If I seem to have laid undue stress on this subject of Individualism, it is because I feel so strongly that just as a nation is judged by the individuals it produces, so our great profession will rise or fall in the eyes of the world according to the character and attainments of its component members. As Disraeli said that for true aristocracy of birth one must look to the Hebrew race, so I believe that for the highest aristocracy of culture and calling one nust turn to the medical profession. Let no man, then, think little of the talents which have been entrusted to him, let no man fancy he can afford to leave one of them undeveloped, for in the position he will be called upon to occupy, and in the fight which he will have to wage with death, disease, ignorance, and bigotry, he will need indeed to be armed at every point. The task may at times seem hard, but life here is but the schooltime of eternity hereafter, and to the labourer who has fought the good fight and over whose existence here the great white wave of oblivion is fast sweeping, sweetly as silve bells across the silent seas of eternity will come the voice of Him who has said, and still loves to say, "Come thou good and faithful servant, enter thou into the joy of thy Lord."

\section{A CASE OF HÆMOGLOBINURIA IN WHICH THE SYMPTOMS FOLLOWED AN ATTACK} OF ACUTE NEPHRITIS.

By DONALD W. C. HOOD, M.D. CintaB, SENIOR PHYSICIAN, NORTH-WEST LONDON HOSPITAL.

H. A-, a lad aged fourteen, was admitted into the North-West London Hospital on Sept. 6th, 1888. Being away from town at this date, the patient was placed under the care of my colleague, Dr. Luff, to whom I am indebted for the earlier notes of the case.

A month before admission the boy had been wet through. A few days later he was ill with headache and vomiting. He then for the first tine passed blood-stained urine. No swelling of any part of the body had been noticed by the patient's mother. The urine continued dark and blood stained up to the date of admission. Previously to this illness the boy's health had been good. Never before this attack, to liis knowledge, had he passed bloody or dark uine. He had not suffered from scarlet fever. There was no history of syphilis or any malarial taint. We could not learn that he had suffered unduly from cold. On anmis sion, the lad looked weak and poorly; there was no oedema of any part of the body; the pulse was soft and compressible, and the temperature subnormal. No disease of cliest. The urine was of a smoky tint, and contained one-twelfth of albumen. There was a copious deposit, dark in colour. This deposit, examined by Dr. Luff, was found to consist of a large number of granular casts, some of which contained blood-corpuscles. 'l'here were also a very consider- able number of free blood-corpuscles. From Sept. [6th to Oct. 2nd, the first day on which I saw the patient, there had been but little change in his general condition, but Dr. Luff especially called my attention to the case in consequence of the persistent, though slight, hæmaturia. $\mathrm{Ta}$ a certain extent, even at this period of the illness, the hromorrhage was intermittent, but at no time was the urine completely free from blood. Albumen ont of proportion to the contained blood was invariably present. The quantity of blood varied from day to day, at no time being large. The urine was generally of a more or less smoky tint, with a dark sediment; at this period of illness was never bright or vinous in colour. On 0ct. 3rd I took some of the deposit home and carefully examined it. I found the same microscopic appearance as deseribed by Dr. Luff. It was a deposit characteristic of nephritis. There were a large number of free blood dises and granular casts. The urine was highly albuminous, of acid reaction: sp. or. 1012. - Oct. 9th: The urine contains more blood. The general condition of the patient remains unaltered. 23rd : For the first time since admission the urine passed this day is of bright port-wine colour. There was a copious deposit, which unfortunately, through a mistake, was thrown away before microscopical examination. - 29th: $0 \mathrm{n}$ this day the urine was clearer than at any previous period of illness. Albumen present in very small quantity.Nov. 6th: The patient had a slight rigor, the temperature running up to $103^{\circ}$. The urine passed subsequently was of darli vinous tint with a copious chocolate-coloured deposit. The attack came on after the boy had been to a cold, draughty watercloset. The deposit from this urine was found to contain a large number of dark granular casts. Much gra* nular débris. A few irregular crenated cerpuscles, evidently blood discs undergoing disintegration. Masses of irregularapparently crystalline-matter of a yellow tint. A few evvelope crystals, and a number of fine, long thin hyaline threa is or casts. In short, the deposit resembled exaetly that seen in cases of hiemoglobinuria. The urine did not clear at once, but remained clouded for ten days. - 25th: The lad suffered from another attack, which commenced with bigh temperature, vomiting, and headache. The boy had been transferred from one ward to another, and it was thoughs possible he might have been chilled during removal. The urine presented the same appearance as on the last occar sion, being of deep vinous colour. The deposit again resembled that found in bæmoglobinuria, and contained no blood-corpuscles.-Dec. 6th : The temperature ran up to $101^{\circ}$. The patient suffered from nausea and headache. The following morning the urine was of port-wine colour, with a dark sediment. - 11th: Slight rise of temperar ture $-99^{\circ}$. The boy vomited and had headache. On the following day the urine was of an intense port-wime colour, with characteristic deposit. From this date the patient began to improve. On Dec. 28 th the urine was recorded as being nearly normal. It contained no blood, was of straw colour, with a slight haze of albumen on adding nitris acid.-30th : Urine smoky; no appreciable sediment.Jan. 2nd, 1889 : Urine dark and smoky; no vinous tint.4th: On this day the urine was practically normal; with nitric acid there was very slight ring of albumen. -5 th : Urine portwine colour, with a slight deposit. - 8th : Uriwe of a vinows tint, with no deposit. It is now three weeks since deposit in any quantity has been present. The patient continued well up to Jan. 15th, on which day he was discharged from hospital. The urine still contained a slight trace of albumen.

The boy was kept under observation up to February, 1890. Since he left the hospital, now more than twelve months, he has had no return of blood-stained urine. On 0ct. 8th, 1889, he was carefully examined; found strong and well, rudily and vigorous; urine very slightly albuninous. $O$ Jan. 10th, 1890, the lad applied again at the hospital, suffering from a mild form of the prevailing epidemicinfluenza. The urine contained more albumen, but the general strength was very good.

During this illness, of about three months' duration, the patient passed through three stages: the stage of an ordinary nephritis, with characteristic urine; the stage of hemoglobinuria, during which the urine which followed the attacks was usually of vinous colour, and contained the deposits met with in this disease; and, lastly, a stage where the urine, although frequently tinted, was without deposit. During the whole course of the illness the intermittent character of the hamorrhage was constantly remarken 
From the first it gave the case unusual interest, and caused the patient to be closely watched.

From the numerous important observations made on cases of hæmoglobinuria, it appears almost beyond doubt that the essential pathology of the disease is a faulty state of the blood-corpuscle, a state of blood-corpuscle which renders it peculiarly liable to speedy or abnormal disintegration. Granting such essential pathology, is it equally certain that the disintegrating process invariably takes place in the systemic circulation? Before the acceptance of such a conclusion it will be well to briefiy consider certain difficulties which appear to contraindicate the general circulation as being in all cases the scene of this peculiar corpuscular disintegration. After a severe paroxysm, the patient a subject of hæmoglobinuria will pass a large quantity (several ounces) of urine, so altered in character that as a fluid it closely resembles blood. In some cases it is only by the microscope that we are able to distinguish between this urine as being symptomatic of ordinary hæmaturia or hæmoglobinuria. As a fluid it is practically blood in solution, and it undoubtedly contains " most, if not all, the constituents of blood." (Dickinson.) Chemically it will vary with the character of the fluid holding the blood in solution. In other words, it will be found to vary with the state of the urine. In one case a specimen of characteristic urine will remain acid for months. A specimen in nny own possession remained acid from March to the end of July. In another alkaline changes will take place within a few hours of its being passed. In the former class the granular semi-crystalline casts preserve their form for a very considerable time; in the latter the casts become broken up as soon as the urine becomes alkaline. This large quantity of blood-stained urine holding in solution an enormous mass of disintegrated corpuscles is usually all passed within a few hours of the initial rigor which ushers in the paroxysm.

I have the notes of a case under my care at the North. West London Hospital. The patient consented to experiment. His hand was iced for half an hour at 5.30 P. M. At 6.15 he complained of feeling very cold, and was placed in bed. At 6.30 the temperature was $1042^{\circ}$. At 7 it was $105^{\circ}$. The patient at this hour passed a large quantity (unfortunately unmeasured) of deep, porter-coloured urine. At $80^{\prime}$ clock the temperature ran up to $106 \cdot 6^{\circ}$. Half an hour later it had fallen two degrees; at 9.30 being $1014^{\circ}$. At 10 P.M. healthy, light-coloured urine was passed. At 11 the temperature was noted as being normal. A drop of blood had been taken from this patient's hand before and after the experiment. Nothing abnormal was noticed. It is, however, right to say that it was only examined with a good quarter-inch. It will be noticed that the patient passed normal urine at 5.30 and again at 10 P.M. In the interval a large quantity of dark portercoloured fluid was voided. This fluid contained an enormous number of disintegrated blood-corpuscles. These corpuscles must have passed repeatedly through the entire circulation if the disintegrating process had occurred in the general circulation, and it would appear almost impossible for this mass of pigmented material to be passing through the circulation and yet cause no discolouration of skin or conjunctiva. In the case I am referring to no such discolouration took place. I am of course aware that in the description given of cases of hæmoglobinuria observers ref $t \mathbf{r}$ to the sallow, yellow tint of skin so often seen; but I think a distinction should be drawn between that icteric, sallow tint of integument which is so characteristic of recurrent attacks and a rapid discolouration akin to jaundice, which would probably follow the sudden liberation of large quantities of pigment in the general circulation. On the other hand, if the kidney be principally concerned in the disintegrating process, there would probably be absorption of some pigment from that organ, with consequent slight icteric tint of skin. There is again another point which at least demands careful examination. Many of the constituents of the urine passed subsequently to an attack are colloidal in character; and as colloids will scarcely pass through membranes with that rapidity which characterises the rapid discharge of the broken-down corpuscles, this rapid discharge of débris is one of the peculiar symptoms of the disease. Sir William Roberts, describing a typical seizure, writes: "The disorder is essentially intermittent or paroxysmal in its nature. Each paroxysm begins with a feeling of cold or shivering, resembling the cold fit of ague, and terminates with the dig- charge of a very dark bloody-looking urine. The symptoms then subside, and the urine at the next micturition or the one after is found to have resumed its healthy appearance." In those cases where through the action of a poison the corpuscles are disintegrated within the general circulation, the débris resulting from this disintegration is not passed from the kidney in a paroxysm; it is thrown off by degrees, and it may be days before complete elimination takes place. This fact was impressed upon me when watching a case of oxalic acid poisoning under my care at the West London Hospital in February, 1886. The patient, a labourer, had swallowed about half an ounce of oxalic acid dissolved in hot tea. For some few days the urine resembled that seen in hamoglobinuria; the dark granular débris resulting from the broken-down corpuscles was not discharged in paroxysms.

This case further exemplified the fact lately insisted upon by Noel-Paton, that in cases where there is corpuscular disintegration within the circulation the amount of urea is largely increased. The urine in the above case was carefully tested for urea, and as much as 700 grains were found to be passing per day. This fact would seem to militate against the theory that in hæmoglobinuria the corpuscles are broken up in the general circulation, for if so the urea should be largely increased. In the cases under my own care the reverse has taken place : the urine of the patient in whom a paroxysm was induced by ice was examined by me, the porter-coloured fluid containing on one occasion $\frac{1}{2}$ per cent., on another 7 per cent., the clear urine subsequently to the attack being 9 percent. Dr. Dickinson, the chief authority on this disease, writing on the presence of urea in hamoglobinuric urine, states that "with regard to the urea during the paroxysm observations conflict ;" he refers to several cases, but none show any great increase, the majority being decidedly under the average. If we now tnrn to those cases in which the blood-corpuscles have become disintegrated through the agency of a poison the result is very different. McKendrick refers to the matter in the following words: "Finally, Noel-Paton has clearly demonstrated that the destruction of blood-corpuseles, and the consequent setting free of hæmoglobin in the blood, causes not only a great increase in the secretion of bile, but also an increase in the amount of urea eliminated by the kidneys." In the experiment referred to by McKendrick the urea after the destruction of corpusclesincreased nearly 12 per cent. It certainly appears anomalous that if in cases of hrmoglobinuria the disintegration of blood-corpuscles does take place in the general circulation, the large amount of hæmoglobin thus set free should not invariably be accompanied by a corresponding increase in the amount of urea discharged. There does not appear to be any relation between the area of chilled surface and the amount of specific urine which is passed subsequently to an attack. A paroxysm produced artificially by applying ice to the hand will be as productive of result-i.e., will produce as large an amount of blood-stained urine-as a chill to a large surface of the body. If the corpuscles be invariably broken up in the general circulation, or in that portion of the circulation directly affected by cold, the amount of débris should surely be more or less proportional to the area of chilled surface. Green-street, W.

\section{ON THE ASSOCIATION OF OXALATE OF LIME CRYSTALS IN THE URINE WITH HAMATURIA OR HÆMOGLOBINURIA.}

BY ALEX. G. R. FOULERTON,

RESIDENT ASSISTANT SURGEON TO ST. BARTHOLOMEW'S HOSPITAL, Chatham.

UNDER the heading of "Hæmaturia and Garden Rhubarb" a correspondence occurred in THE LANCET of June 28th and July 5th. In this correspondence several instances were recorded in which the eating of the vegetable was followed by the passage of blood and oxalate of lime crystals in the urine. I do not think that in these cases the exact state of the urine was so recorded that one could say whether the condition present would be better described as hæmaturia or hæmoglobinuria, but for my present purpose, and because of the not infrequent association of the two conditions, this omission is not of any great consequence. It is a matter of common knowledge that in some individuals oxaluria is prone to 